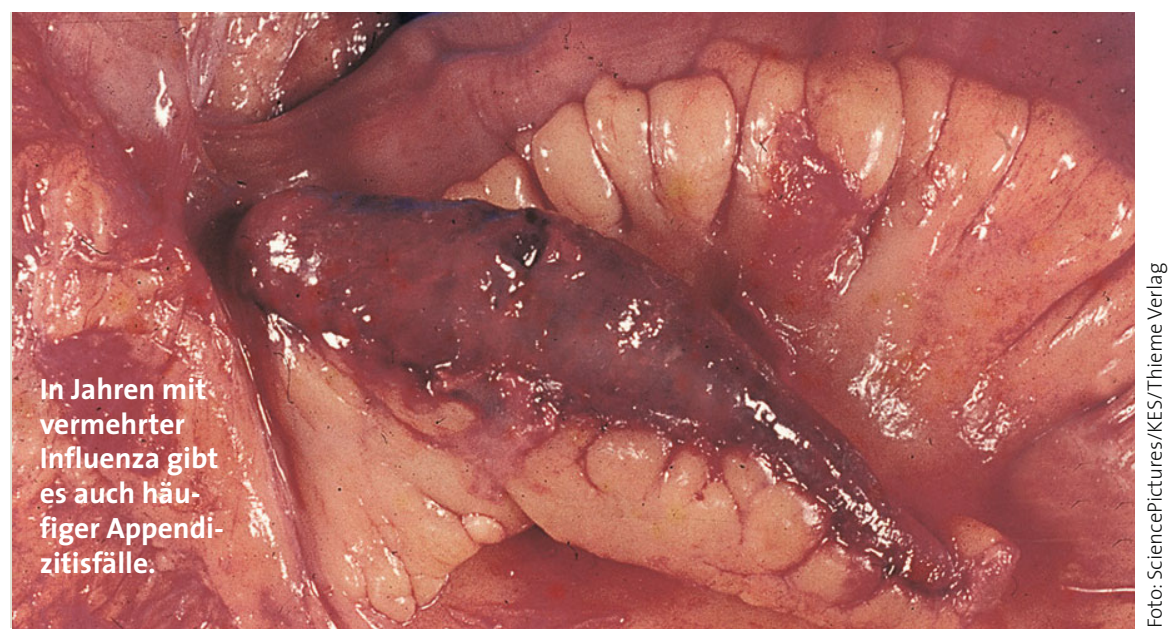

\title{
Ist die Appendizitis mit Virusinfektionen assoziiert?
}

Die Ursachen der Appendizitis sind nicht bekannt. Nach neueren epidemiologischen Studien könnten aber Beziehungen zu Virusinfektionen bestehen. Amerikanische Forscher haben untersucht, ob zwischen der Appendizitis und bestimmten viralen Infektionskrankheiten ein Zusammenhang besteht.

- Forscher der University of Texas in Dallas analysierten in einer großen epidemiologischen Studie die Abschlussberichte aller US-amerikanischen Krankenhäuser der Jahre 1970 bis 2006. Identifiziert wurden alle Appendizitisfälle und verschiedene Viruskrankheiten wie die durch Influenza-, Rotavirus- und Magen-Darm-Viren.

Von 1970 bis 1995 fielen die Influenza- und Appendizitisraten progressiv $\mathrm{ab}, \mathrm{um}$ danach wieder anzusteigen. Aber die Influenzaraten hatten deutlichere Saisonmuster. Zwischen Infektionen mit dem Rottavirus und anderen Virusinfektionen und der Appendizitis konnte kein Zusammenhang erkannt werden. Die Inzidenz von Darminfektionen nahm über die Jahre zu, hatte aber keinen Bezug zu den Appendizitisfällen. Die perforierende Appendizitis zeigte ein anderes Verteilungsmuster als die nicht perforierende. Hier konnte auch kein Zusammenhang mit Virusinfektionen erkannt werden.

KOMMENTAR: Weder die Influenza noch das Rotavirus kommen als Verursacher der Appendizitis infrage, weil die saisonalen Beziehungen zwischen diesen Krankheiten fehlen. Schließlich fällt die Grippewelle immer in den Winter, Blinddarmentzündungen hingegen häufen sich eher im Sommer. Da es jedoch in Jahren mit einer erhöhten Influenzainzidenz auch mehr Appendizitisfälle gibt, könnte es pathogenetische Mechanismen oder Umweltfaktoren geben, die die Inzidenz dieser Erkrankungen ähnlich beeinflussen. Dass die Inzidenz des Blinddarmdurchbruchs diesem Muster nicht folgt, könnte darauf verweisen, dass es sich bei der Appendizitis mit oder ohne Durchbruch um völlig verschiedene Entitäten handelt und ein Durchbruch nicht unbedingt die Folge einer normalen Entzündung sein muss. Sollte sich das bestätigen, dann müsste die Regel, jede Appendizitis so schnell wie möglich zu operieren, noch einmal überdacht werden.

K. MALBERG =

\section{A. C. Alder et al.}

(Divisions of Gastrointestinal and Endocrine Surgery and Epidemiology, University of Texas Southwestern Medical Center, Dallas, USA) Association of viral infection and appendicitis. Arch. Surg. 145 (2010) 163-171 